\title{
Postcardiotomy shock: Which patients benefit from extracorporeal membrane oxygenation?
}

\author{
Rochus K. Voeller, MD, and Rosemary Kelly, MD
}

\author{
From the Division of Cardiothoracic Surgery, University of Minnesota, Minneapolis, Minn. \\ Disclosures: Authors have nothing to disclose with regard to commercial support. \\ Received for publication June 26, 2018; accepted for publication June 28, 2018; available ahead of print Aug 21, \\ 2018. \\ Address for reprints: Rosemary Kelly, MD, Division of Cardiothoracic Surgery, University of Minnesota, 425 \\ Delaware St, SE, Mayo Mail Code 207, Minneapolis, MN 55455 (E-mail: kelly071@umn.edu). \\ J Thorac Cardiovasc Surg 2018;156:1883-4 \\ $0022-5223 / \$ 36.00$ \\ Copyright (C) 2018 by The American Association for Thoracic Surgery \\ https://doi.org/10.1016/j.jtcvs.2018.06.084
}

Fux and colleagues ${ }^{1}$ address the rare but complex clinical problem of how and when to use venoarterial (VA) extracorporeal membrane oxygenation (ECMO) support for patients experiencing postcardiotomy cardiogenic shock (PCS). This is a timely addition to the literature because the role of ECMO in adult patients needing cardiac care is rapidly evolving. ECMO has been increasingly used in the adult population as a salvage maneuver since 2009 when it was successfully used in adult patients with florid pulmonary failure from viral influenza pneumonia. ${ }^{2}$ This prompted a similar expansion to adult cardiac populations as a bridge to recovery from PCS and other acute cardiomyopathies, as well as additional support for patients receiving a left ventricular assist device or undergoing heart and lung transplant. ${ }^{3}$ Despite the significantly increased use for VA ECMO, there has not been an improvement in mortality in the adult cardiac population. ${ }^{4}$ In particular, patients with PCS treated with ECMO have the worst outcomes for all ECMO indications, with an overall mortality of $60 \%{ }^{5}$ The ability to identify patients with PCS who will successfully recover before the institution of VA ECMO is a critical gap in knowledge.

The authors ${ }^{1}$ present a unique perspective from a single institution regarding pre-ECMO predictors of 90-day survival following PCS. They defined PCS as the clinical condition of shock refractory to intravascular volume loading, pharmacologic treatment, and intra-aortic balloon pump support. The literature identifies this occurrence in $0.5 \%$ to $1.5 \%$ of cardiac surgery patients and states that it will lead to death unless more efficient circulatory support is initiated. ${ }^{6}$ Because Fux and colleagues ${ }^{1}$ achieved an excellent overall $57 \%$ survival of PCS supported with VA ECMO to 90 days, they retrospectively reviewed their experience to identify pre-ECMO risk factors or parameters that may determine objective criteria for appropriate use of ECMO in PCS. They compared survivors with nonsurvivors at 90 days in a cohort of 105 patients. They found the presence of ischemic heart disease and elevated

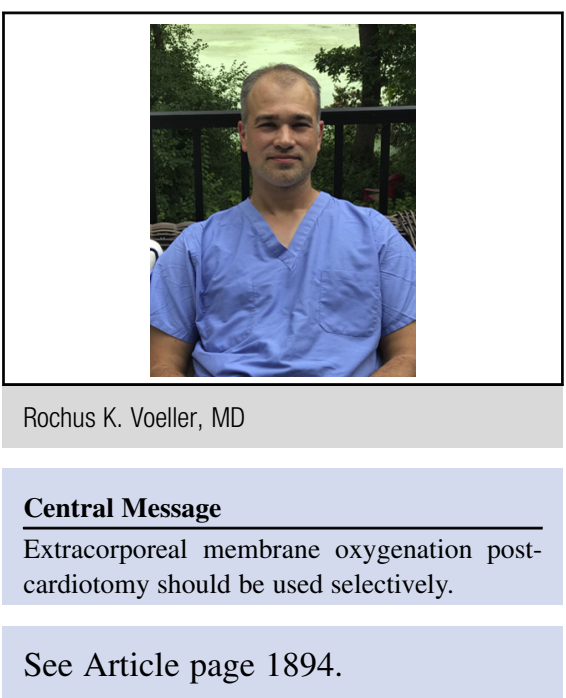

arterial lactate levels to be key indicators of poor outcome. Similarly, Loforte and colleagues ${ }^{7}$ also used lactate levels as a predictor of mortality for patients with PCS supported on ECMO, but their determination was made after 72 hours of ECMO. Fux and colleagues ${ }^{1}$ present findings that a preECMO lactate level $\geq 10 \mathrm{mmol} / \mathrm{L}$ corresponds to $91 \%$ mortality and a level $\geq 15 \mathrm{mmol} / \mathrm{L}$ is associated with $100 \%$ mortality. This finding may in itself be a critical contribution to the decision of when not to institute ECMO support. The worse outcome associated with ischemic heart disease is not unexpected due to severity of irreversible myocardial injury. Awareness of the influence of ischemic heart disease, along with other variables associated with mortality such as low ejection fraction and advanced age, may appropriately influence the decision to initiate ECMO support. In addition, only 2 of 105 patients studied were bridged to transplant or left ventricular assist device placement. Fux and colleagues ${ }^{1}$ provide objective guidance regarding PCS device support that will hopefully assist in difficult but realistic decision making for surgeons and family.

Although Fux and colleagues have started the conversation, it is necessary to continue to study long-term outcomes, disposition, and cost analyses in regard to the utility of PCS recovery with ECMO. The patient population is problematic because the cohort reflects patients treated with a salvage therapy and includes a range of clinical scenarios. The current literature lacks clear definitions or inclusion criteria for PCS and specifics about ECMO technique 
and decision making for timing are sparse. As ECMO becomes an increasing reality in the care of cardiac patients, setting parameters for when therapy is futile is critical to ethical care. This article provides important first steps in defining pre-ECMO criteria.

\section{References}

1. Fux T, Holm M, Corbascio M, Lund LH, van der Linden J. Venoarterial extracorporeal membrane oxygenation for postcardiotomy shock: risk factors for mortality. Thorac Cardiovasc Surg. 2018;156:1894-902.

2. Schmid C, Philipp A, Hilker M, Rupprecht L, Arlt M, Keyser A, et al. Venovenous extracorporeal membrane oxygenation for acute lung failure in adults. $J$ Heart Lung Transplant. 2012;31:9-15.
3. Khorsandi M, Dougherty S, Bouamra O, Pai V, Curry P, Tsui S, et al. Extracorporeal membrane oxygenation for refractory cardiogenic shock after adult cardiac surgery: a systematic review and meta-analysis. J Cardiothorac Surg. 2017; $12: 55$.

4. Whitman GJ. Extracorporeal membrane oxygenation for the treatment of postcardiotomy shock. J Thorac Cardiovasc Surg. 2017;153:95-101.

5. McCarthy FH, McDermott KM, Kini V, Gutsche JT, Wald JW, Xie D, et al. Trends in U.S. extracorporeal membrane oxygenation use and outcomes: 2002-2012. Semin Thorac Cardiovasc Surg. 2015;27:81-8.

6. Golding LA. Postcardiotomy mechanical support. Semin Thorac Cardiovasc Surg. 1991;3:29-32.

7. Loforte A, Marinelli G, Musumeci F, Folesani G, Pilato E, Martin Suarez S, et al. Extracorporeal membrane oxygenation support in refractory cardiogenic shock: treatment strategies and analysis of risk factors. Artif Organs. 2014;38: E129-41. 